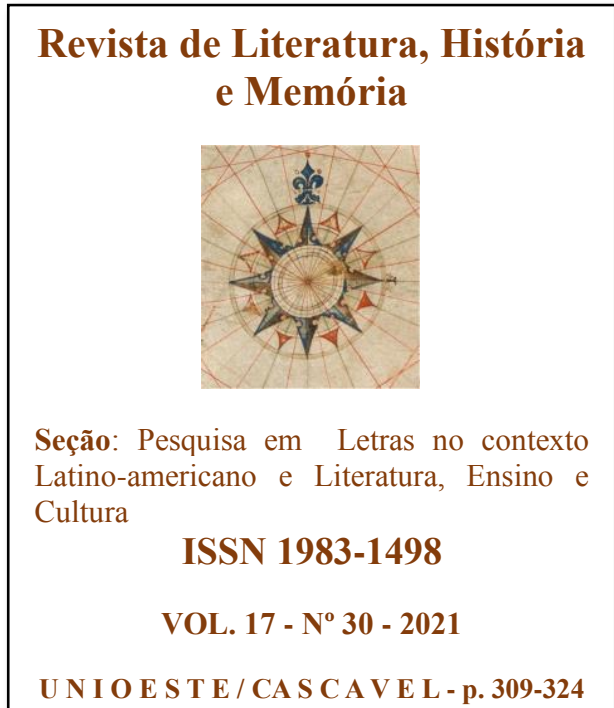

\title{
LA CRÍTICA HACIA LA INMOVILIDAD CULTURAL DE CHILE, EN UN AÑN (1935) DE JUAN EMAR
}

\author{
Criticism towards cultural immobilism of Chile, in Un \\ año (1935) by Juan Emar
} año (1935) by Juan Emar

Kakyung Lee ${ }^{1}$

RESUMEN: La novela de Juan Emar, Un año (1935), consta de doce capítulos que ocurren, o al menos se registran, en el primer día de cada mes del año. Este análisis se enfoca en la furia que siente el narrador-personaje en los meses de mayo, junio y julio. En este artículo, se propone que la furia del narrador-personaje reflejaría la frustración de Juan Emar como miembro de una élite vanguardista en la sociedad apática y tradicionalista de Chile en los años veinte y treinta. El análisis considera los siguientes puntos, con atención especial al contexto sociopolítico de la obra: Juan Emar es un artista de la vanguardia dentro de Chile, en los años veinte del pasado siglo; la furia está dirigida a las instituciones sociales, a la sociedad en sí y a la élite chilenas; la metáfora del insecto que aparece en mayo representaría la incapacidad del narradorpersonaje para cambiar el ambiente cultural de Chile.

PALABRAS-CLAVE: Un año; Juan Emar; Chile; Furia; Inmovilidad.

ABSTRACT: Juan Emar's novel, Un año (1935), consists of twelve chapters on episodes that occurred or at least it is said to be recorded on the first day of each month. This analysis focuses on the fury felt by the narrator-protagonist that appears in May, June and July. The paper proposes that the narrator-protagonist's fury reflects Juan Emar's frustration as a Chilean avant-garde elite, battling against Chile's traditionalist and immobile society in the 1920s and 1930s. The following points will be examined, with emphasis on the sociopolitical context of the work: Juan Emar is an avant-garde artist in the nineteen twenties; the fury is directed towards social institutions, the society and the Chilean elite; the metaphor of the insect that appears in May represents the protagonist's inability to reform the cultural environment of Chile.

KEYWORDS: Un año; Juan Emar; Chile; Fury; Immobilism.

\section{INTRODUCCIÓN: LA FURIA DE UN AÑN (1935)}

Juan Emar (1893-1964) fue un escritor chileno perteneciente al Grupo Montparnasse ${ }^{2}$ que seguía el movimiento vanguardista. El vanguardismo influyó en todas sus obras literarias, inclusive la que examina este análisis. Un año (1935), consta de doce capítulos que ocurren, o al menos se registran, en el primer día de cada mes del año. Es posible suponer que el

\footnotetext{
${ }^{1}$ Aluna de Pós-Graduação em Literatura Hispanoamericana na Universidade Nacional de Seul (Coreia do Sul). Licenciada em Língua e literatura hispânica e em estudos de Estética (Filosofia) pela mesma Universidade.

${ }^{2}$ El Grupo Montparnasse, formado en 1922, era un conjunto de artistas chilenos influidos por el movimiento vanguardista de Europa, en especial Francia, de donde viene su nombre. El grupo tomó la iniciativa de diseminar las ideas vanguardistas en la práctica del arte plástico en Chile (FUNDACIÓN JUAN EMAR, 2001).
} 
narrador-personaje es alter ego de Emar puesto que se comparten las mismas iniciales del nombre, “J. E.” (EMAR, 1935, p. 73). En algunos de los meses, mayo, junio y julio, un sentimiento de furia llama la atención del lector. En junio y julio, el narrador-personaje se siente furioso con frecuencia. Junio comienza con la exclamación de que sentía tres furias: "Hoy he vivido de furia en furia, rebotando así, una, dos, tres, una furia, otra furia y otra más" (EMAR, 1935, p. 20). Julio termina con otra furia: "Hoy, por lo tanto, y nuevamente, ira contra Dios" (EMAR, 1935, p. 37). También en mayo, aunque no menciona de manera explícita la furia personal, se citan los Cantos de Maldoror, aludiendo una posible reacción furiosa por parte del lector: “«Plugue al cielo que el lector, envalentonado y sintiéndose momentáneamente feroz como lo que lee»” (EMAR, 1935, p. 18).

Esta novela cuenta con estudios que la analizan, por lo general, en función de la obra total de Juan Emar (BURGOS, 2004; ÁNGEL GALLARDO, 2016). Pero los pocos que se han dedicado a Un año no se detienen a revisar dicho sentimiento (ESPINOSA HERNÁNDEZ, 2003; RUBIO, 2008; LIZAMA, 2010). Los artículos que examinan la furia no la relacionan con el contexto sociopolítico de la obra. Por ejemplo, el estudio de Soledad Traverso-Rueda (1996, p. 215) explica que la ira viene de la clarividencia limitada: "El personaje queda, por lo tanto, atrapado entre la realidad objetiva (continuum) y la unidad que percibe como resultado de la clarividencia, pero en la cual no puede permanecer. [...] Esta condición genera la ira y el hastío".

Pablo Catalán (2000, p. 99) menciona la furia cuando examina todos los meses de $U n$ año y ofrece una explicación semejante: "Frente a las furias objetivas, se repiten las furias subjetivas del personaje-narrador [...], desempeñando, contra su voluntad, el papel de Dios omnisciente y todopoderoso".

El presente artículo se enfoca en los meses donde aparece expresada la furia, que son mayo, junio y julio, con el objetivo de responder a la cuestión de cuál sería el origen o el motivo de la furia que siente el narrador-personaje. Se propone que la furia del narradorpersonaje reflejaría la frustración de Juan Emar como miembro de una élite vanguardista en la sociedad apática y tradicionalista de Chile, en las décadas del 20 y 30 . El análisis sigue cinco puntos con atención especial al contexto sociopolítico: I) Juan Emar es un artista de la vanguardia en el Chile de las primeras décadas; II) la furia está dirigida a las instituciones sociales, III) a la sociedad en sí, y IV) a la élite chilena; finalmente, V) el 'bicho' que aparece en mayo representaría la incapacidad del narrador-personaje para cambiar el ambiente cultural de Chile. 


\title{
JUAN EMAR DENTRO DEL CONTEXTO CHILENO
}

Juan Emar, desde una perspectiva de la élite vanguardista, criticaba el escenario artístico y cultural de Chile que era reacio a las reformas de vanguardia. Álvaro Yáñez Bianchi usaba el pseudónimo 'Juan Emar' que significa "estoy harto, hasta la coronilla" (LIZAMA, 1994, p. 945), lo que podría interpretarse en relación con sus ideas vanguardistas. Pudo aprender las tendencias más modernas del arte en Francia, con el apoyo de su padre, Eliodoro Yáñez, presidente del diario La Nación (LIZAMA, 1994, p. 949) Su estancia en Europa coincidió con el período del surgimiento de la vanguardia artística (BURGOS, 2004, p. 83). Cuando regresó a Chile en 1923, Emar llevó consigo el vanguardismo europeo y desempeñó un papel importante en la difusión de las expresiones vanguardistas en Chile (LIZAMA, 1994, p. 945). El Grupo Montparnasse del que era miembro marcó una ruptura en el arte plástico de Chile al introducir esa tendencia de arte más moderna (LIZAMA, 1994, p. 950). Además, sus propias obras literarias representan el estilo vanguardista (LIZAMA, 1994, p. 945). Emar vio la necesidad de divulgar el vanguardismo especialmente en su país donde dominaba la tradición del arte académico:

\begin{abstract}
El arte académico no era solamente un modo de pintar, una tendencia pictórica, sino que era un verdadero sistema artístico autosuficiente. Sus intelectuales y artistas provenían de un circuito de élites surgido de la clase dirigente. [...] Su dominio se establecía a través de la interacción de una pluralidad de instituciones culturales que aseguraban la reproducción del mundo simbólico de la clase dirigente. Una de ellas era la Academia de Pintura, más tarde llamada Escuela de Bellas Artes. [...] Otra instancia significativa lo constituían los Consejo de Bellas Artes. También la crítica de arte contribuía a difundir y legitimar el arte académico que el público, la clase dirigente y el gobierno consagraba económica y socialmente. (LIZAMA, 1994, p. 945).
\end{abstract}

Los artistas como Emar no podían alcanzar el éxito fuera de ese sistema establecido (LIZAMA, 1992, p. 11). Cuando publicó sus obras literarias no fueron bien recibidas porque había impugnado esas instituciones, a los críticos y lectores de su momento con sus ideas vanguardistas. Como defensor del vanguardismo, tuvo éxito al promoverlo en el campo pictórico de Chile, pero no en el literario (LIZAMA, 1994, p. 953). Los críticos y el público ignoraron sus obras literarias que no se conformaban a las reglas del naturalismo, que era la norma para las novelas en aquella época (LIZAMA, 1994, p. 945). Daniel Rojas Pachas (2021) también confirma que "la literatura de este autor chileno 'resignadamente moderno' y consciente de su fracaso, propone ya en esos primeros años del siglo XX, el agotamiento de 
las formas y los pastiches que serían importados desde Europa a nuestro continente".

Su trayectoria de reformar el arte chileno es evidente en "Notas de Arte (1923-1925)", ensayos críticos que escribió y publicó en el diario La Nación que pertenecía a su padre, al regresar de Francia (NIEMEYER, 2004, p. 413). Estos artículos golpeaban el arte hegemónico chileno:

En su primer artículo publicado, 'Algo sobre pintura moderna', hizo un análisis de las condiciones de recepción de la pintura contemporánea en Chile. Para Emar, los profesores de la Academia, los pintores académicos (también los llamaba oficiales) y los críticos de arte eran los principales oponentes de las nuevas expresiones plásticas, pues las ignoraban o las descalificaban. La consecuencia inevitable era que el público no entendía y censuraba la pintura de vanguardia. (LIZAMA, 1992, p. 14).

El conflicto dentro del plano chileno prueba que los objetivos vanguardistas de Emar no fueron universales sino regionales. Ese país que trató de revolucionar puede considerarse como el contexto de Un año. Por ejemplo, se deja en claro que está situado en Chile cuando se contrasta Chile y Francia, en el capítulo de julio. Desde los referentes directos e indirectos de Chile, podría interpretarse la novela de Emar en el contexto sociohistórico chileno de su época. Entonces, los tres focos de furia, las estructuras sociales, la sociedad en sí y la élite, como identificaría luego, serían las entidades inmóviles de Chile contra las que luchó Juan Emar. Las furias se distinguen por tener diferentes causas y existe un orden consecutivo entre la furia que explora el narrador-personaje en la trama de los meses de junio y julio. En cada mes, el narrador-personaje se enfoca primero en las estructuras sociales, después en los miembros de la sociedad y, finalmente, en la clase de la élite.

\section{LA FURIA HACIA LAS ESTRUCTURAS SOCIALES DE CHILE}

El narrador-personaje clasifica sus furias en diferentes categorías. "Primera: ira contra mí mismo. Segunda: ira contra los demás. Ahora: ira contra Dios" (EMAR, 1935, p. 28). Como las furias no son iguales, el narrador-personaje afirma la necesidad de distinguirlas. "Furia. Mas distingamos. Hay un distingo que da la clave de por qué ésta -la de las sombrasvino a colocarse encima de la otra -la de las viejas-, sin mezclarse en una furia total" (EMAR, 1935, p. 23).

La causa de la primera furia, en junio y julio, son las estructuras sociales de Chile. Al mismo tiempo, el narrador-personaje se siente furioso consigo mismo, debido a que asume 
una postura de élite que sufre menos que los de la clase baja ante los problemas sociales. Analizaremos la furia hacia la sociedad teniendo en cuenta el contexto sociopolítico de Chile en ese momento.

En junio, siente la primera furia cuando observa a once viejas harapientas enfrente de la Escuela de Altos Estudios Politécnicos:

Salí de casa. Frente a la Escuela de Altos Estudios Politécnicos había un grupo de viejas harapientas que hacían cola, al lado de la puerta principal. Por cierto estaban en espera del algo, pero ¿qué pueden esperar once viejas de la Escuela de Altos Estudios Politécnicos? Esta pregunta me atravesó como un proyectil. ¿Qué pueden esperar? Y fué suficiente: la furia me dominó. [...] ¿Qué pueden esperar de la Escuela de Altos Estudios Politécnicos once viejas harapientas? (EMAR, 1935, p. 20-21).

El narrador-personaje repite tres veces la misma pregunta que le provoca un impacto como de proyectil, como dice en la cita. Podría estar planteando una cuestión sociopolítica sobre la relación entre los pobres, las mujeres y la educación. El narrador-personaje, desde la perspectiva defendida en este artículo, hace alusión a que en los años treinta de Chile no existía ningún vínculo entre la educación politécnica y quienes tenían el doble peso de ser pobres y mujeres.

En aquel tiempo, "la educación era inexistente o muy deficiente para los niños de los sectores populares. De partida, el $25 \%$ de la población era completamente analfabeta" (PORTALES, 2018). Encima, la educación parecía igual para todo, pero la de los hombres y las mujeres se diferenciaba en cuanto al contenido. Por ejemplo, podemos encontrar en la Ley Orgánica de Instrucción Primaria de 1860 que la educación de las mujeres se centraba en las asignaturas domésticas, que era lo que quería criticar Emar: "En las escuelas superiores para mujeres se sustituirá a la enseñanza del dibujo lineal i de la Constitución Política, la de la economía doméstica, costura, bordado i demás labores de aguja" (MINISTERIO DE INSTRUCCIÓN PÚBLICA DE LA REPÚBLICA DE CHILE, 1911, p. 4). Aunque la Ley de Educación Primaria Obligatoria promulgada en 1920 garantizaba para niños y niñas la oportunidad gratuita de recibir educación, en realidad no había igualdad de género por los currículos sexistas:

La escuela primaria del bajo pueblo ofreció un curriculum similar para niños y niñas. No así las escuelas superiores y el liceo. Las políticas educativas del siglo XIX y comienzos del XX, dan cuenta de las posiciones ideológicas en torno al rol de la mujer en la sociedad, la disputa por el contenido de su formación escolar y el ideal de ciudadanía femenina de aquel momento. La 
idea de que educar una mujer estaba al servicio de educar a una buena madre de familia fue transversal en los discursos políticos de los hombres de la elite. [...] La distinción entre hombres y mujeres operaba en los cursos más avanzados para las escuelas superiores. [...] Por tanto, existió igualdad de contenidos en un nivel inicial, pero en los niveles posteriores al 4to grado, se establecían distinciones por sexo y una clara división en lo relativo a los trabajos manuales. Esta diferencia curricular se asentaba en una cultura patriarcal que concebía el rol de las mujeres en el espacio doméstico, mientras que la educación de los hombres se vinculaba con los temas públicos y el trabajo asalariado. (ROJAS FABRIS; ASTUDILLO, 2020 p. 119-120).

En contraste con las mujeres harapientas, el narrador-personaje asume una posición de élite:

Pues, al fin y al cabo, yo iba por las calles y pasaba frente a dicha Escuela: $1^{\circ}$.) gozando de todas las prerrogativas de libertad a que es acreedor en una República modelo, todo ciudadano honesto, y $2^{\circ}$.) gozando ampliamente de mi propia libertad que, desde el momento de despertar, había decidido no formular a mi mente pregunta alguna. (EMAR, 1935, p. 21).

Además de reconocerse como "ciudadano honesto" de "una República modelo" con derecho a no preocuparse por nada como atributo de su libertad, también señala:

En el primer caso las viejas fueron el pretexto que inflamó mi furia. Pero mi furia entera recayó sobre mí mismo, y las viejas, mal que mal, quedaron excluidas de ella. Mi furia tal vez rondaba en torno mío. [...] Se apodera de mí porque la interrogación me envuelve, estrujándome y preguntándome cómo es posible que el hombre soberano pueda ser detenido ante la primera contradicción callejera que no atina a esclarecer: la ancha puerta de la Escuela de Altos Estudios Politécnicos alargando desde su umbral por la acera once viejas harapientas. (EMAR, 1935, p. 23-24).

Es clara la distinción entre el narrador-personaje, quien tiene todos los derechos de la sociedad, y las viejas que sufren por los problemas callejeros. Las mujeres no incluidas en la categoría de 'ciudadano' revelan la desigualdad de la sociedad chilena. Para el narradorpersonaje, la puerta de la escuela es ancha, mientras que las mujeres apenas tienen el derecho de esperar delante de la escuela como sombras. La infraestructura social injusta de Chile fomenta la furia del protagonista que está dirigida a sí mismo como un castigo por no sufrir ni darse cuenta del problema.

En otro pasaje de la obra, el personaje expone un accidente de tráfico. Este accidente que se narra en julio, también cuestiona la sociedad: 
Iba yo por una avenida central de gran movimiento. De pronto un accidente: una góndola y un auto se estrellan. Tumulto, vociferaciones y demás. Dos hombres se abofetean. Heridos, un muerto, Asistencia Pública, carabineros. En un momento me pareció que aquello iba a cambiar el rumbo de la ciudad entera, por ende del país. Pero en un minuto, acaso en menos, todo se apaciguó. Como por obra de magia fue la desaparición general: querellantes, policías, Asistencia Pública, curiosos, todo. Volvió la circulación normal de la avenida sin conservar ni una huella de lo ocurrido, ni una sola. (EMAR, 1935, p. 31-32).

Se enfatiza el impacto del accidente en la sociedad, denotando que tuvo lugar en una avenida central y que llegaron acumulándose las fuerzas gubernamentales. Aun así, luego de un momento, todo volvió a ser como antes y el país no cambió. Por la inmovilidad social, Estanislao Buin pasa por el sitio del accidente sin saber lo que había ocurrido:

Pasó al lado -iqué!-, encima, pisoteando, taconeando, el sitio mismo, el punto exacto donde, segundos antes, se estrellan dos vehículos, se abofetea la gente, se hieren varios, fallece uno y acude el orden público. Y pasa, repito, por allí mismo, pasa, $[\ldots]$ sin saberlo, sin haberlo sabido, sin ir a saberlo jamás. (EMAR, 1935, p. 32).

Es posible deducir que está acusando a las estructuras sociales por sostener un mundo sumido en la ignorancia, ya que el narrador-personaje se refiere, específicamente, a las principales instituciones de la sociedad, como la Asistencia Pública, la Policía y el Orden público. En esta parte de la narración, se reconoce que tanto las estructuras sociales como los organismos del gobierno contribuyen a la incompetencia colectiva que impide la toma de conciencia de lo que ocurre en su entorno.

\section{LA FURIA HACIA LA SOCIEDAD CHILENA}

La segunda furia del narrador-personaje está dirigida a la gente inmóvil e impasible de la sociedad. En junio, el narrador-personaje observa desde una posición elevada a los hombres de abajo. Está asomado en el balcón de su amigo. Sigue la narración del contraste entre él y los demás de la clase baja que no tienen lucidez:

Total: nueve amigos ascendentes: el primer piso es un amigo grande y sincero; pero el segundo, lo es más; y el del tercero, más. Y así, a medida que suben los pisos, sube también la amistad que nos une; hasta el noveno. [...] Mas cuando alguna pasión empieza a removerse dentro de mí, voy trepando por las escaleras en proporción exacta de la potencia de tal pasión.

(EMAR, 1935, p. 22). 
A medida que suben los pisos, suben la amistad y la fuerza de la emoción del narrador-personaje. La altura física se relaciona con la magnitud de lo metafísico. De aquí, podríamos inferir que la elevación simboliza la elevación en poder. El narrador-personaje ocupa la posición de élite, "suelto y aislado en la radiante mañana de un balcón" (EMAR, 1935, p. 24) y siendo un "hombre puro, elevado en el marco de un balcón amigo" (EMAR, 1935, p. 26). Su amigo da más importancia a la hermosura de la mañana que al problema de la educación y advierte que la disfruta. Sin embargo, cuando mira abajo, el narrador-personaje de repente se siente furioso: "Segunda furia: Irremediablemente una sombra para cada hombre. Pero hay cólera, odio a muerte, contra todos los demás hombres que pasan por el asfalto, hombres que pasan del costado sombrío de la calle al costado del sol esplendoroso" (EMAR, 1935, p. 23-24).

La razón es que la gente camina sin consciencia del conocimiento más básico. La gente no nota sus sombras que cambian al andar. El narrador-personaje se decepciona al ver que se mantienen inconmovibles y no piensan en cuestionar su entorno. Se burla de la gente que toma por dado el mundo:

¡Hombres cobardes! Por lo menos si uno, uno sólo durante el día, de pie al centro de la calzada, protestara a voz en cuello, los puños alzados contra el cielo, protestara al desparramar sombra en el sol, protestara al no dibujar con brillo de ascuas su silueta sobre el pavimiento sombrío. ¡Nada! ¡Hombres cobardes! Mi cólera mortal va hacia ellos. (EMAR, 1935, p. 25).

También en julio, el narrador-personaje golpea la mediocridad de la gente. Antes, el narrador-personaje andaba por la avenida central y criticaba la sociedad. En esa parte, camina “al modo del paseante benjaminiano" (ESPINOSA HERNÁNDEZ, 2003, p. 108) por donde vive la gente y critica a un individuo. Este personaje simboliza a la sociedad inconsciente que destaca "como uno de los más preclaros representantes de nuestra imbecilidad" (EMAR, 1935, p. 33). Lo odia porque permanece inmóvil a pesar de que era necesario que viera al narrador-personaje:

Este personaje desea verme, necesita verme, mi presencia o no presencia ante él puede variarle en favor o en contra su destino. [...] Resumen: él allí dentro; yo por la calle pasando. Paso frente a su casa, lentamente. Soy su destino, un posible cambio en su destino que él anhela y necesita. Las 3 y 33 exactas. Frente a su ventana. Tras ella, el hombre sumido en sus viejos pergaminos. Paso. (EMAR, 1935, p. 33).

Si el hombre hubiera levantado la vista, habría visto al narrador-personaje pasando 
lenta y cercanamente, hasta el punto de alcanzar a ver la punta en el pergamino y la mosca:

No ha sabido, no, que parte de su destino acaba de pasar, lentamente, junto a él, que habría bastado un paso hacia adelante para hallar la ocasión casual de enderezar tantas líneas que se le han torcido en su existencia. No ha sabido nada. ¡Nada! Ni siquiera un estremecimiento en una punta de una hoja de un pergamino. Ni una mosca inoportuna que le obligase, justo a las 3 y 33, a cortar su labor con algún gesto diferente. ¡Nada! (EMAR, 1935, p. 34).

El discurso del personaje en la obra puede leerse como una alusión a la sociedad que tiene una visión limitada y rutinaria, incapaz de cambiar su destino. Por ello, el narradorpersonaje siente cansancio y fatiga. Podríamos concluir que, en junio y julio, el narradorpersonaje expresa su furia hacia la gente inconsciente de Chile que no cabe en las ideas vanguardistas de Emar.

\section{LA FURIA HACIA LA ÉLITE DE CHILE}

La élite chilena no puede evitar, finalmente, la furia del narrador-personaje. En junio, después de subir al noveno piso, el piso más alto, el narrador-personaje se fija en la clase de la élite: "No vuelvo a mirar las calles. Ahora miro al frente, otra casa, grande como ésta en que estoy. Ventanas y más ventanas. Por ellas atisbo hacia la vida interior" (EMAR, 1935, p. 26). La casa de enfrente pertenecería a la clase más alta porque tiene la misma altura, como el noveno piso desde donde lo contempla.

La gente de la élite también es ignorante. Por ejemplo, el narrador-personaje observa que una mujer podría morir, pero ella permanecía ignorante de su situación. Se distingue entre el narrador-personaje y la élite inconsciente, el narrador-personaje puede ver la totalidad de la casa mientras que ellos no pueden verse entre sí. El narrador-personaje destaca que está aparte, con otros designios, comparándose con la élite que queda apática. Repite frases que lo comparan directamente con la élite: "jamás, jamás sería sabido por aquellos. [...] Y sí por mí" (EMAR, 1935, p. 29); "Yo lo habría sabido. Pero el vejete aquel, no" (EMAR, 1935, p. 30). El narrador-personaje siente ira contra Dios porque ha compartido la percepción clara solo con él. Ni la sociedad en general ni la élite tienen esta toma de conciencia. El mes termina con la declaración de que el narrador-personaje preferiría un menor protagonismo: "sin distracciones ni vislumbres, [el] rol de hombre gusano que se arrastra y que, si es mucho su desamparo, llame y clame, ante todo a los infiernos" (EMAR, 1935, p. 31). Es una agonía para el narrador-personaje ver la inmovilidad de la élite que hasta prefiere no percibir la 
situación.

Igualmente, en julio, degrada a la élite ignorante. El narrador-personaje espera al cínico de Valdepinos cuyo epíteto hace creer que es una élite astuta. Puesto que es cínico, anticipa que va a criticar su entorno que es lo que el narrador-personaje quería que hiciera la sociedad chilena. Por eso, tiene esperanzas de que el cínico comparta su clarividencia y pueda gozar de un reposo para la fatiga de antes: "Mas por la noche, hoy por la noche, vendría la distracción, por lo tanto, el reposo. Comería con nosotros, con mi hermano Pedro y yo, el cínico de Valdepinos. Cínico será, pero su charla, justamente cínica, disipa, por eso mismo, toda modorra, toda preocupación" (EMAR, 1935, p. 34).

El narrador-personaje se decepciona con el cínico porque no mira alrededor y no nota la botella de Pernod, la bebida francesa que era su mayor deleite. El cínico nunca se da cuenta de la botella, aunque Pedro, hermano del narrador-personaje, la eleva por veinticuatro segundos: "Durante veinticuatro segundos -repito- el mayor deleite de ese hombre ha estado sobre él, se ha detenido allí detrás él. Una vuelta de ojos, y habríamos agotado hasta el último sorbo y otras habrían sido nuestras ideas, otras nuestras andanzas y seguramente otros nuestros destinos" (EMAR, 1935, p. 36).

Al final, en junio y julio, todos los personajes de la élite han quedado como ignorantes, menos el protagonista. Así, el escritor vanguardista critica la incapacidad de la élite para mirar su entorno. La soledad en su causa vanguardista invoca la furia: "Hoy, por lo tanto, y nuevamente, ira contra Dios" (EMAR, 1935, p. 37).

\section{LA FRUSTRACIÓN DEL NARRADOR-PERSONAJE}

El tema común que transcurre a través de junio y julio es la búsqueda de clarividencia, pero el narrador-personaje fracasa en este intento. Vaga por la ciudad desde la mañana hasta la noche con la intención de encontrar a otra persona que sepa lo que él sabe. En junio, pasa la mañana en la ciudad sin encontrar a nadie. Finalmente, baja del noveno piso hacia las calles de la ciudad y la escena continúa en julio donde camina por una avenida central. Por la tarde de julio, es testigo del accidente y pasa por la casa de su amigo. En la noche de julio, cena con el cínico de Valdepinos. Cuando contemplamos que el tiempo de la novela no es lineal, deducimos que el narrador-personaje ha pasado un día entero buscando a otra gente perceptiva, pero que ha fallado.

Sin embargo, en mayo, hay un ser que comparte esa clarividencia. El narradorpersonaje entra en su biblioteca y descubre una bestezuela que se ha comido las palabras de 
los Cantos de Maldoror. La bestezuela de mayo y el narrador-personaje son figuras paralelas representando a una élite solitaria con un destino de fracaso. La soledad del narradorpersonaje coincide con la de la bestezuela: "Había sido atacado por sólo un bichito, nada más que por uno" (EMAR, 1935, p. 17). El animalito se hallaba muerto sobre la mesa, pero el narrador-personaje oye un leve rumor producido por el insecto carcomiendo el libro. Pese a que ya había muerto cuando entró el narrador-personaje en su biblioteca, ya que no había entrado durante diecisiete años, el narrador-personaje explica la vida del bicho. Así, recorre la vida del insecto identificándose con el bicho.

La bestezuela se come las páginas de los Cantos de Maldoror (1869) que denuncian la inmovilidad y que alaban a los animales que muerden y atacan (THACKER, 2013, p. 86). André Breton denominó a su autor, el Conde de Lautréamont, como uno de los precursores del surrealismo vanguardista (THACKER, 2013, p. 83). De este modo, el insecto se convierte en un activista del vanguardismo. Al devorar la obra de Lautréamont, la bestezuela absorbe desde la palabra final hasta la primera, adquiriendo el sentido de las palabras en sentido inverso:

Mas no como cualquier espíritu superficial lo imaginaría, no recto hacia arriba, no, de ningún modo. Lo había seguido en plano inclinado, en plano oblicuo, trepando suavemente, en ángulo muy agudo, trepando segura, precisa, exacta en su fino túnel de tinta y de papel, en demanda de la primera letra de la primera palabra de la primera línea del primer canto. (EMAR, 1935, p. 18).

También confirma que el bicho había perforado la letra final de la palabra final. Este insecto que había absorbido la obra prevanguardista siguiendo una trayectoria no convencional se correspondería con el narrador-personaje. Ambos son elogiados en el texto: “¡Noble bestezuela!” (EMAR, 1935, p. 19-20). Cabe mencionar que el narrador-personaje tiene el rol de Dios y la bestezuela está comparado con Cristo: "Se había traspasado con toda la desolación «abrupta y salvaje» de esas 280 páginas de «pantanos envenenados» y había recibido en su cuerpito diminuto -como un nuevo Cristo de nuestros últimos hermanos-" (EMAR, 1935, p. 19).

Por otro lado, la bestezuela es un ser insignificante que podría interpretarse como la incapacidad de realizar su deseo, ya que el narrador-personaje lo encuentra muerto. Así también representa la situación del narrador-personaje que fracasa en descubrir otra gente con clarividencia. Se describe al animalito y su trabajo con palabras como "levísimo rumor" (EMAR, 1935, p. 17), “trituración [...] microscópica” (EMAR, 1935, p. 17), “su simple 
sistema nervioso" (EMAR, 1935, p. 19). Podría suponerse que el bicho fuera un piojo porque carcomió "hoja por hoja, el himno al piojo" (EMAR, 1935, p. 19) del libro. En este himno, se describe el deseo de los piojos de devorar no solo la sangre sino al humano entero, pero la imposibilidad de hacerlo radica en la falta de fuerza:

«No sabéis vosotros por qué no os devoran los huesos de la cabeza, contentándose con extraer con su bomba, la quintaesencia de vuestra sangre. Esperad un instante, os lo voy a decir: es porque la fuerza les falta. Estad ciertos que, si sus mandíbulas fuesen conformes a la medida de sus votos infinitos, el cerebro, la retina de los ojos, la columna vertebral, todo vuestro cuerpo entre ellas pasaría». (EMAR, 1935, p. 19, comillas del textø).

En junio, aparece la palabra piojo otra vez, describiendo la limitación de su rol de Dios. Aunque puede ver más que la gente ignorante, describe su capacidad de "ver en globo" (visión global) usando el término "piojo" como sinónimo de pequeñez: "Pues yo, en el balcón del noveno amigo y frente a mis vecinos, hacía en pequeño, en miniatura, en piojo el rol de ver en globo [...] lo que los de ese mismo globo veían seccionado. Un aspecto de rol de Dios” (EMAR, 1935, p. 28).

El bicho representaría al narrador-personaje, un ser que devora libros pero que al mismo tiempo carece de poder para lograr sus objetivos. El texto de Emar agrega, después de la cita de Los cantos de Maldoror, que el insecto agradece al autor por comprender y exaltar la empresa de los piojos: "entonces la bestezuela, desde su prisión sombría, elevó hacia Lautréamont sus «votos infinitos» de infinito reconocimiento" (EMAR, 1935, p. 19-20). El canto segundo de la obra del poeta francés dice:

Hay un insecto que los hombres alimentan a su costa. [...] sería capaz, gracias a un poder oculto, de hacerse tan grande como un elefante y aplastar a los hombres como espigas. Hay que ver cómo se le respeta, cómo se le rodea de una veneración canina, cómo se le coloca en la más alta estima por encima de los demás animales de la creación. Se le otorga la cabeza como trono. (LAUTRÉAMONT, 1988, p. 177).

No obstante, el reconocimiento a la empresa del insecto, tanto en el canto de Lautréamont como en Un año, fracasa en su deseo de beber cuanto pueda la sangre y hasta los órganos humanos. Igualmente, el protagonista de Emar no alcanza a cumplir su deseo de promover la reforma vanguardista en su país. 


\section{CONCLUSIÓN: LA ÉLITE VANGUARDISTA FRENTE A LA APATÍA CHILENA}

El análisis de Patricio Lizama de Un año sostiene: "La posición emariana entonces se distancia del color local y del realismo socialista para postular un pensamiento crítico que autónomo y situado, se enfrenta al infinito. [...] La función del escritor no pasa por una denuncia abierta de los conflictos político-sociales" (LIZAMA 2010, p. 106-107). Sin embargo, nuestro análisis muestra que la furia del narrador-personaje se basa en el contexto sociohistórico de Chile, en su época. Como hemos revisado, la furia de Juan Emar se origina por la inmovilidad de Chile ante las renovaciones vanguardistas. Al mismo tiempo, la élite intelectual no reconoce los problemas sociales de los chilenos y la frustración del narradorpersonaje se refleja en la aparición de la bestezuela de mayo.

El primer punto que explica este análisis es que Juan Emar era un artista que deseaba introducir el vanguardismo en Chile, en las décadas veinte y treinta del siglo XX. Podemos ver que las obras de Emar también reflejaban la política chilena. Su vanguardismo se preocupaba no solo de la estética sino de la política contemporánea:

La vanguardia es siempre la ruptura de un sistema artístico prevalente por otro que emerge. Pero la vanguardia también es ruptura con el conjunto del campo cultural: instituciones, aparatos formativos, aparatos de comunicación y los agentes culturales que ocupan estas posiciones. (LIZAMA, 1992, p. 20).

En junio y julio de Un año, vimos que el narrador-personaje critica, primero, las estructuras de la sociedad, segundo, a la gente y, tercero, la clase alta de la élite chilena. Todos permanecieron inamovibles frente a la urgencia de reformas, aunque no debieron ser tan apáticas en los años treinta. En 1929, la Gran Depresión de Estados Unidos afectó seriamente los sectores principales de exportación en Chile: "el impacto más significativo de la crisis en 1930 fue, sin duda, una caída de alrededor de un 40 por ciento en las exportaciones" (MORENO, 2013, p. 8). A principios de la década de 1930, dicha crisis derivó en la inestabilidad política por la incapacidad de los gobernantes ante los graves problemas socioeconómicos:

El 4 de junio de 1932 se destituyó al Presidente de la República, Esteban Montero, y se constituyó una Junta de Gobierno integrada por Arturo Puga, Carlos Dávila y Eugenio Matte, quienes preocupados por pan, techo y abrigo para el pueblo, declararon fundada la República Socialista. (PALMA GONZÁLEZ, 2017, p. 376). 
A principios del siglo XX, Chile padecía de pobreza, falta de educación e inestabilidad gubernamental. El Ministro de Salud, Javier Castro Oliveira, al dejar su cargo en 1936, dijo: “«como una cámara cinematográfica, nuestros conventillos pudieron transmitir una imagen del infierno más real que la de Dante»” (PORTALES, 2018).

Finalmente, en mayo, el narrador-personaje y el piojo sienten la energía furiosa del vanguardismo. El hecho de que no puedan cambiar nada aumenta su frustración. El narradorpersonaje no ha usado su biblioteca donde encuentra al bicho durante diecisiete años. Diecisiete años antes de la publicación de Un año sería 1918, cuando ocurren las "Marchas del Hambre" como consecuencia de la crisis económica de Chile (TASSO VALDÉS, 2013). La economía chilena dependía de la exportación de salitre, la cual disminuyó a finales de la Primera Guerra Mundial debido a que el salitre utilizado para explosivos ya no se necesitaba (COLLIER; SATER, 1996, p. 202). El narrador-personaje entra nuevamente a su biblioteca en 1935, cuando Chile requiere una reforma de nuevo.

Así, este trabajo ha expuesto los cinco puntos mencionados en la introducción: Un año se sitúa dentro del contexto chileno; Emar critica las instituciones sociales, a la sociedad, a la élite chilena; la frustración del narrador-personaje se trasmite a través de la metáfora del bicho. En una primera lectura, Un año parecería ser una novela fantástica o metafísica donde los personajes no dudan en desenvolverse ante elementos surrealistas. Efectivamente, este autor chileno era uno de los pioneros de vanguardismo en Chile: "Emar perturba por entero el canon literario de Chile y América con una producción que constituye un enigma visionario, para el tiempo en que se gestó (el primer cuarto del 1900)" (ROJAS PACHAS, 2021). La obra de Juan Emar se basa en los contextos sociales y políticos de su país y de su época, según hemos propuesto en nuestra lectura, de manera que se revela el nivel sociopolítico del texto, al mismo tiempo que hemos tratado de responder a la pregunta del porqué de la furia desde un punto de vista sociohistórico chileno.

\section{REFERENCIAS}

ÁNGEL GALLARDO, Roberto. Un análisis narratológico sobre la obra de Juan Emar. Revista de Letras, 2016, v. 56, n. 2, p. 149-162.

BURGOS, Fernando. La situación de Juan Emar en la vanguardia. In: Actas del XIV Congreso de la Asociación Internacional de Hispanistas. Nueva York: Juan de la CuestaHispanic Monographs-AIH-Fundación Duques de Soria-City University of New York, 2004, t. 4 , p. 83-89. 
CATALÁN, Pablo. Dos estudios sobre Juan Emar. Mapocho. Revista de Humanidades y Ciencias Sociales, 2000, n. 48, p. 81-138.

COLLIER, Simon; SATER William F. A History of Chile, 1808-1994. Cambridge: Cambridge University, 1996.

EMAR, Juan. Un año. Santiago de Chile: Editorial Zig-Zag, 1935.

ESPINOSA HERNÁNDEZ, Patricia. Un año de Juan Emar: Intertextualidades, metatextualidades y ontología del fragmento. Aisthesis, 2003, n. 36, p. 108-115.

FUNDACIÓN JUAN EMAR, Grupo Montparnasse. Artículos/Estudios, 2001. http://www.fundacionjuanemar.com/articulos estudios.html. Acceso en: 21 ago. 2021.

LAUTRÉAMONT. Obra completa. Bilingüe. Trad. Manuel Álvarez Ortega. Madrid: Eds. Akal, 1988.

LIZAMA, Patricio. Introducción. In: Jean Emar. Escritos de Arte (1923-1925). Santiago de Chile: Dirección de Bibliotecas, Archivos y Museos, 1992, p. 9-21.

Jean Emar/Juan Emar: la vanguardia en Chile. Revista Iberoamericana, 1994, v. 60, n. $168-169$, p. $945-959$.

. Un Año de Juan Emar: El artista de vanguardia en una modernidad periférica. Revista Chilena de Literatura, 2010, n. 77, p. 95-108.

MORENO, Ignacio. La Gran Depresión en Chile: Lecciones macroeconómicas. Estudios Nueva Economía II, 2013, v. 2, n. 1, p. 5-17.

NIEMEYER, Katharina. Subway de los sueños, alucinamiento, libro abierto: La novela vanguardista hispanoamericana. Frankfurt am Main: Vervuert Verlagsgesellschaft, 2004.

PALMA GONZÁLEZ, Eric Eduardo. El Estado socialista según la legislación irregular de Carlos Dávila (junio-septiembre de 1932). Estudios constitucionales, 2017, v. 15, n. 1, p. 373-404.

PORTALES, Felipe. Extrema miseria en Chile en los años 30. Sur y Sur, 2 ene. 2018. https://www.surysur.net/extrema-miseria-en-chile-de-los-anos-30. Acceso en: 14 ago. 2021.

MINISTERIO DE INSTRUCCIÓN PÚBLICA DE LA REPÚBLICA DE CHILE. Disposiciones relativas al Servicios de Instrucción Primaria. Santiago de Chile: Soc. Imprenta y Litografía Universo, 1991.

ROJAS FABRIS, María Teresa; ASTUDILLO LIZAMA, Pablo. Igualdad de género en la educación: Un siglo de debates. Avances y desafíos. In: A 100 años de la Ley de Educación Primaria Obligatoria. La educación chilena en el pasado, presente y futuro. Santiago de Chile: Universidad Alberto Hurtado, 2020, p. 119-129.

ROJAS PACHAS, Daniel. Juan Emar, un visionario que anticipa el modernismo tardío. Cine y Literatura, 7 jul. 2021. https://www.cineyliteratura.cl/ensayo-juan-emar-un-visionario-que- 
anticipa-el-modernismo-tardio/. Acceso en: 21 ago. 2021.

RUBIO, Cecilia. El método iniciático de Rudolf Steiner en Un año de Juan Emar. Anales de Literatura Chilena, 2008, n. 10, p. 53-67.

TASSO VALDÉS, José Luis. Las 'Marchas del Hambre' y la Asamblea Obrera de Alimentación Nacional (AOAN) 1918-1920. Revista Rufián, 22 dic. 2013. Disponible en: https://rufianrevista.org/portfolio/las-marchas-del-hambre-y-la-asamblea-obrera-dealimentacion-nacional-aoan-1918-1920-1/. Acceso en: 14 ago. 2021.

THACKER, Eugene. Apophatic Animality: Lautréamont, Bachelard, and the Bliss of Metamorphosis. Angelaki. Journal of Theoretical Humanities, 2013, v. 18, n. 1, p. 83-98.

TRAVERSO-RUEDA, Soledad. Juan Emar: La angustia de vivir con el dedo de Dios en la nuca. Un estudio de la narrativa vanguardista de Juan Emar. 1996. Tesis (Doctorado en Filosofía). College Park: Universidad de Maryland, 1996. 